Article

\title{
Semi-Synthesis and Evaluation of Sargahydroquinoic Acid Derivatives as Potential Antimalarial Agents
}

\author{
Tatenda C. Munedzimwe ${ }^{1}$, Robyn L. van $\mathrm{Zyl}^{2}{ }^{2}$, Donovan C. Heslop ${ }^{2}$, Adrienne L. Edkins ${ }^{3}[$ and \\ Denzil R. Beukes ${ }^{4, *}$ \\ 1 Faculty of Pharmacy, Rhodes University, Grahamstown 6139, South Africa; tatendamunedzimwe@gmail.com \\ 2 Pharmacology Division, Department of Pharmacy and Pharmacology, WITS Research Institute for \\ Malaria (WRIM), MRC Collaborating Centre for Multidisciplinary Research on Malaria, \\ Faculty of Health Sciences, University of the Witwatersrand, Johannesburg 2000, South Africa; \\ robyn.vanzyl@wits.ac.za (R.L.v.Z.); donoheslop@gmail.com (D.C.H.) \\ 3 Biomedical Biotechnology Research Unit (BioBRU), Department of Biochemistry and Microbiology, \\ Rhodes University, Grahamstown 6139, South Africa; a.edkins@ru.ac.za \\ 4 School of Pharmacy, University of the Western Cape, Bellville 7535, South Africa \\ * Correspondence: dbeukes@uwc.ac.za; Tel.: +27-021-959-2352
}

Received: 25 February 2019; Accepted: 28 March 2019; Published: 1 April 2019

\begin{abstract}
Background: Malaria continues to present a major health problem, especially in developing countries. The development of new antimalarial drugs to counter drug resistance and ensure a steady supply of new treatment options is therefore an important area of research. Meroditerpenes have previously been shown to exhibit antiplasmodial activity against a chloroquinone sensitive strain of Plasmodium falciparum (D10). In this study we explored the antiplasmodial activity of several semi-synthetic analogs of sargahydroquinoic acid. Methods: Sargahydroquinoic acid was isolated from the marine brown alga, Sargassum incisifolium and converted, semi-synthetically, to several analogs. The natural products, together with their synthetic derivatives were evaluated for their activity against the FCR-3 strain of Plasmodium falciparum as well as MDA-MB-231 breast cancer cells. Results: Sarganaphthoquinoic acid and sargaquinoic acid showed the most promising antiplasmodial activity and low cytotoxicity. Conclusions: Synthetic modification of the natural product, sargahydroquinoic acid, resulted in the discovery of a highly selective antiplasmodial compound, sarganaphthoquinoic acid.
\end{abstract}

Keywords: sargaquinoic acid; sarganaphthoquinoic acid; antiplasmodial; malaria

\section{Introduction}

Despite the impressive breakthroughs in the treatment of malaria [1], it remains a life-threatening disease. Southeast Asia and sub-Saharan Africa account for the vast majority of the estimated 219 million malaria cases reported worldwide, leading to 435,000 deaths [2]. More than $90 \%$ of malaria cases and deaths occur in Africa, of which more than $70 \%$ are children under five years of age [2]. The prospect of resistance to current drugs appears inevitable and paints a bleak picture indeed [3]. Although the reasons for this dire situation are complex, there is undoubtedly a need for the continued search for and development of new antimalarial drugs. Natural products have historically offered some of the most effective antimalarial drugs [4]. In a previous study, we reported on the antiplasmodial activity of natural products isolated from the South African brown seaweed, Sargassum incisifolium, against a chloroquine sensitive strain of Plasmodium falciparum (D10) [5]. S. incisifolium is relatively abundant along the South African coastline and produces sargahydroquinoic acid (1) as the major metabolite. The accessibility of $\mathbf{1}$ thus provided an opportunity to explore the structure activity 
relationships of analogs of this natural product. Herein we report on the antiplasmodial activity of semi-synthetic analogs of sargahydroquinoic acid (1) (Figure 1).

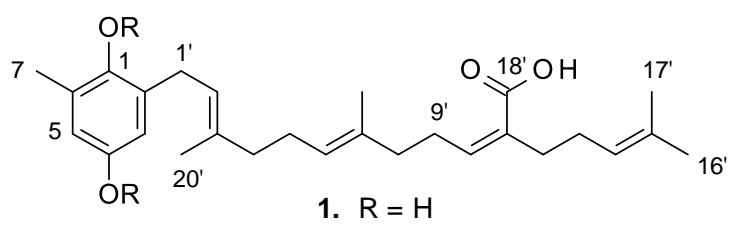

2. $R=O A C$<smiles>[R]CC(=O)OCCC/C(C)=C/CCC1(C)C=Cc2cc(O)cc(C)c2O1</smiles>

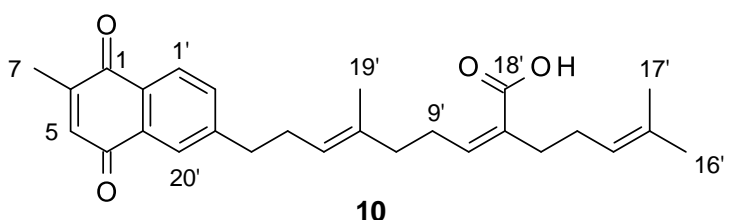<smiles>[R]C(=CCC/C(C)=C/CC/C(C)=C/CC1=CC(=O)C=C(C)C1=O)CCC=C(C)C</smiles>

3. $\mathrm{R}=\mathrm{COOH}$

4. $\mathrm{R}=\mathrm{CHO}$

5. $\mathrm{R}=\mathrm{COOMe}$

6. $\mathrm{R}=\mathrm{CH}_{2} \mathrm{OH}$<smiles>CC(C)=CCC/C(C=O)=C\CC/C(C)=C/CC/C(C)=C/CC1=CC(=O)C=C(C)C1=O</smiles>

Figure 1. Natural and semi-synthetic derivatives of sargahydroquinoic acid (1).

\section{Materials and Methods}

\subsection{General Experimental}

All solvents were of chromatographic grade (Merck, Darmstadt, Germany) and used without further purification. Column chromatography was performed on silica gel (40-63 $\mu \mathrm{m}$ particle size) from Merck, Darmstadt, Germany. Normal Phase HPLC was carried out using a Whatman Partisil 10 semi-preparative column (Sigma-Aldrich, Schnelldorf, Germany) (10 mm $\times 500 \mathrm{~mm}, 10 \mu \mathrm{m})$, while a Phenomenex Luna $C_{18}$ column (Sigma-Aldrich, Schnelldorf, Germany, $10 \mathrm{~mm} \times 250 \mathrm{~mm}, 10 \mu \mathrm{m}$ ) was used for reversed phase HPLC. NMR spectra were recorded on Bruker Avance $400 \mathrm{and} 600 \mathrm{MHz}$ spectrometers (Bruker Biospin, Rheinstetten, Germany) and referenced to residual undeuterated $\mathrm{CDCl}_{3}$ solvent signals $\left(\delta_{\mathrm{H}} 7.26 \mathrm{ppm}\right.$ and $\left.\delta_{\mathrm{C}} 77.0 \mathrm{ppm}\right)$. UV spectra were measured on a Perkin Elmer Lambda 25 UV/Vis spectrometer (Perkin-Elmer, Norwalk, CT, USA) while FT-IR data was obtained using a Perkin Elmer Spectrum 100 FT-IR spectrometer (Perkin-Elmer, Norwalk, CT, USA). High resolution electrospray ionization mass spectroscopy (HR-ESIMS) spectra were obtained on a Waters Synapt G2 mass spectrometer (Waters Corporation, Milford, MA, USA) at $20 \mathrm{~V}$.

\subsection{Extraction and Isolation of Natural Products}

Specimens of Sargassum incisifolium were collected from Port Alfred (collection code PA071b) on the south east coast of South Africa on 21 September 2007 and stored at $-20^{\circ} \mathrm{C}$. The samples were authenticated by comparison with voucher specimens from previous studies [5]. Voucher specimens are stored at the School of Pharmacy, University of the Western Cape.

The following isolation protocol is representative and was repeated several times in order to generate sufficient quantities of $\mathbf{1}$ for synthetic modification. The frozen alga ( $38.77 \mathrm{~g}$, extracted dry weight) was allowed to thaw at room temperature after which it was soaked in methanol for one hour. The methanol was removed and the alga extracted three times with $\mathrm{MeOH}-\mathrm{CH}_{2} \mathrm{Cl}_{2}(1: 2)$ at $40{ }^{\circ} \mathrm{C}$ for $30 \mathrm{~min}$. Extracts were pooled and separated into aqueous and organic phases by the addition of 
distilled water. Concentration of the organic phase under reduced pressure gave a dark green residue $(3.87 \mathrm{~g})$. A portion of the organic fraction $(1.09 \mathrm{~g})$ was fractionated by step-gradient elution on a silica gel column $(10 \mathrm{~g})$ using solvents of increasing polarity (n-hexane-EtOAc) to give seven fractions as follows: Fr A (H-E, 10:0, 8.6 mg), Fr B (H-E, 9:1, 27 mg), Fr C (H-E, 8:2, 132 mg), Fr D (H-E, 6:4, 218 mg), Fr E (H-E, 4:6, 65 mg), Fr F (H-E, 2:8, $9.7 \mathrm{mg}$ ) and Fr G (H-E, 0:10, $50 \mathrm{mg}$ ) followed by MeOH-EtOAc (1:1), Fr 7H (238 mg). Fraction B (19 mg) was further purified by silica gel column chromatography using a mobile phase of $n$-hexane-EtOAc (9:1) to give $1.7 \mathrm{mg}$ of sargaquinal (9). Fraction C (40 mg) was purified by normal phase HPLC using $n$-hexane-EtOAc as mobile phase (8:2) to give $15 \mathrm{mg}$ of sargaquinoic acid (3). Fraction D (20 mg) was purified by reversed phase HPLC using $\mathrm{MeOH}-\mathrm{H}_{2} \mathrm{O}$ phase (90:10) as the mobile phase to give sargahydroquinoic acid (1) $(6.8 \mathrm{mg})$ and sargachromenol (7) (2.4 mg), respectively. The isolation of compounds 1, 3, 7 and 9 is summarised in Scheme S1 and their structures were confirmed by spectroscopic methods, which were in agreement with literature data (Table S1) [5]. The NMR spectra for compounds 1 (Figures S1 and S2), 3 (Figures S3 and S4), 7 (Figures S5 and S6) and $\mathbf{9}$ (Figures S7 and S8) are presented in the Supplementary Materials.

\subsection{Sargaquinoic Acid (3) and Sarganaphthoquinoic Acid (10)}

To a solution of $\mathbf{1}(154.0 \mathrm{mg}, 0.36 \mathrm{mmol})$ in a mixture of $\mathrm{CHCl}_{3}(8 \mathrm{~mL})$ and $\mathrm{MeOH}(7 \mathrm{~mL})$ was added $\mathrm{Ag}_{2} \mathrm{O}(100 \mathrm{mg}, 0.43 \mathrm{mmol})$. The reaction mixture was stirred at room temperature for $24 \mathrm{~h}$, after which the resulting suspension was filtered through diatomaceous earth and concentrated under reduced pressure. The crude product was filtered through a plug of charcoal ( $n$-hexane-EtOAc, 4:6) to give a yellow mixture of compounds which was separated by silica gel column chromatography (n-hexane-EtOAc, 7:3) to give sargaquinoic acid (3) (80 mg, 70\%) and compound $10(9.8 \mathrm{mg}, 6 \%)$ as light yellow oils. NMR spectra for compound 10 (Figures S9-S14) can be found in the Supplementary Materials.

Sarganaphthoquinonoic acid (10): IR (film) $v_{\max }\left(\mathrm{cm}^{-1}\right)$ : 1600, 1663, 2850, 2924; ${ }^{1} \mathrm{H}$ and ${ }^{13} \mathrm{C}$ NMR data see Table 1; HRESIMS m/z 419.2222 [M-H] (calcd. for $\mathrm{C}_{27} \mathrm{H}_{35} \mathrm{O}_{3}, 419.2221$ )

Table 1. NMR spectroscopic data for sarganaphthoquinoic aicd (10) (600 and $125 \mathrm{MHz}, \mathrm{CDCl}_{3}$ ).

\begin{tabular}{|c|c|c|c|c|c|}
\hline Carbon Number & $\delta_{C}$ & Type & $\delta_{\mathrm{H}}$, mult, $J(\mathrm{~Hz})$ & COSY & НМВС \\
\hline 1 & 185.4 & $\mathrm{C}$ & - & & \\
\hline 2 & 130.2 & $\mathrm{C}$ & - & & \\
\hline 3 & 132.2 & $\mathrm{C}$ & - & & \\
\hline 4 & 185.4 & $\mathrm{C}$ & - & & \\
\hline 5 & 136.0 & $\mathrm{CH}$ & $6.81, \mathrm{~s}$ & $\mathrm{H}-7$ & \\
\hline 6 & 149.0 & C & - & & \\
\hline 7 & 16.4 & $\mathrm{CH}_{3}$ & $2.18, \mathrm{~s}$ & $\mathrm{H}-5$ & $C-6, C-5$ \\
\hline $1^{\prime}$ & 126.7 & $\mathrm{CH}$ & $8.00, d, 7.9$ & $\mathrm{H}-2^{\prime}$ & C-2, C-1 \\
\hline $2^{\prime}$ & 133.8 & $\mathrm{CH}$ & $7.51, d, 7.9$ & $\mathrm{H}-4^{\prime}, \mathrm{H}-20^{\prime}$ & $C-1, C-20^{\prime}$ \\
\hline $3^{\prime}$ & 148.2 & $\mathrm{C}$ & - & & \\
\hline $4^{\prime}$ & 36.2 & $\mathrm{CH}_{2}$ & $2.77, \mathrm{t}, 7.6$ & H-5' & $C-5^{\prime}, C-3^{\prime}$ \\
\hline $5^{\prime}$ & 29.1 & $\mathrm{CH}_{2}$ & $2.36, \mathrm{~m}$ & $\mathrm{H}-4^{\prime}, \mathrm{H}-6^{\prime}$ & $C-4^{\prime}, C-6^{\prime}, C-7^{\prime}$ \\
\hline $6^{\prime}$ & 123.2 & $\mathrm{CH}$ & $5.17, \mathrm{~m}$ & & \\
\hline $7^{\prime}$ & 136.0 & $\mathrm{C}$ & - & & \\
\hline $8^{\prime}$ & 39.0 & $\mathrm{CH}_{2}$ & $2.08, \mathrm{~m}$ & $\mathrm{H}-9^{\prime}$ & C-6' \\
\hline $9^{\prime}$ & 28.2 & $\mathrm{CH}_{2}$ & $2.57, \mathrm{~m}$ & $\mathrm{H}-10^{\prime}$ & $C-8^{\prime}, C-10^{\prime}$ \\
\hline $10^{\prime}$ & 145.0 & $\mathrm{CH}$ & $5.96, t, 7.3$ & $\mathrm{H}-9^{\prime}$ & C- $8^{\prime}$ \\
\hline $11^{\prime}$ & 130.6 & C & - & & \\
\hline $12^{\prime}$ & 27.8 & $\mathrm{CH}_{2}$ & $2.26, \mathrm{~m}$ & $\mathrm{H}-13^{\prime}, \mathrm{H}-14^{\prime}(\mathrm{lr})$ & $C-13^{\prime}, C-14^{\prime}$ \\
\hline $13^{\prime}$ & 28.2 & $\mathrm{CH}_{2}$ & $2.11, \mathrm{~m}$ & $\mathrm{H}-14^{\prime}$ & C- $15^{\prime}, \mathrm{C}-11^{\prime}$ \\
\hline $14^{\prime}$ & 123.4 & $\mathrm{CH}$ & $5.17, \mathrm{t}, 7.0$ & $\mathrm{H}-13^{\prime}, \mathrm{H}-14^{\prime}$ (lr) & \\
\hline $15^{\prime}$ & 132.3 & $\mathrm{C}$ & - & & \\
\hline $16^{\prime}$ & 25.6 & $\mathrm{CH}_{3}$ & $1.68, \mathrm{~s}$ & $\mathrm{H}-14^{\prime}(\mathrm{lr})$ & C- $15^{\prime}, C-14^{\prime}$ \\
\hline $17^{\prime}$ & 17.7 & $\mathrm{CH}_{3}$ & $1.59, \mathrm{~s}$ & $\mathrm{H}-14^{\prime}(\mathrm{lr})$ & C- $16^{\prime}$ \\
\hline $18^{\prime}$ & 171.9 & C & - & & \\
\hline $19^{\prime}$ & 15.9 & $\mathrm{CH}_{3}$ & $1.58, \mathrm{~s}$ & H- $6^{\prime}$ & C-6' \\
\hline $20^{\prime}$ & 125.9 & $\mathrm{CH}$ & $7.86, \mathrm{~s}$ & $\mathrm{H}-4^{\prime}$ & $C-4^{\prime}, C-4$ \\
\hline
\end{tabular}

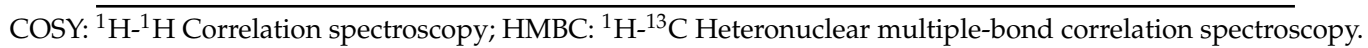




\subsection{Sargaquinoic Acid Methyl ester (5)}

To a solution of $\mathbf{1}$ (122.4 mg, $0.29 \mathrm{mmol})$ dissolved in $2 \mathrm{~mL}$ acetone, was added $\mathrm{K}_{2} \mathrm{CO}_{3}(207.4 \mathrm{mg}$, $1.50 \mathrm{mmol})$ in $5 \mathrm{~mL}$ acetone and dimethylsulphate $(250 \mu \mathrm{L}, 2.63 \mathrm{mmol})$. The mixture was heated at $40{ }^{\circ} \mathrm{C}$ for $8 \mathrm{~h}$ followed by stirring at room temperature for $16 \mathrm{~h}$. The reaction mixture was filtered, concentrated under reduced pressure and separated by silica gel column chromatography ( $n$-hexaneEtOAc, 8:2) to give the methyl ester of $\mathbf{1}$, which, upon exposure to air was completely oxidized to 5 . NMR spectra for compound 5 (Figures S15-S16) can be found in the Supplementary Materials.

Yellow oil, ${ }^{1} \mathrm{H}$ NMR $\left(400 \mathrm{MHz}, \mathrm{CDCl}_{3}\right) \delta 6.52(1 \mathrm{H}, \mathrm{s}, \mathrm{H}-3), 6.44(1 \mathrm{H}, \mathrm{s}, \mathrm{H}-5), 5.83(1 \mathrm{H}, \mathrm{t}, J=7.0 \mathrm{~Hz}$, H-10'), 5.10 (3H, m, H-2', H-6', H-14'), 3.71 (3H, s, OMe), 3.11 (2H, d, J = 6.8 Hz, H-1'), 2.49 (2H, m, H-9'), 2.22 (2H, m, H-12'), 2.05 (2H, m, H-4') 2.03-2.05 (6H, m, H-5', H-8', H-13'), 1.65 (6H, s, H-7, H-19'), $1.61\left(3 \mathrm{H}, \mathrm{s}, \mathrm{H}-20^{\prime}\right), 1.58$ (3H, s, H-16'), 1.55 (3H, s, H-17'); 188.0 (C-1, C-4), 168.4 (C-18'), 148.4 (C-6), 145.8 (C-2), 142.1 (C-10'), 140.0 (C-3') 134.8 (C-7') 133.1 (C-3, C-15'), 132.1 (C-5), $131.4\left(\mathrm{C}-11^{\prime}\right), 124.4$ (C-6'), $123.5\left(\mathrm{C}-14^{\prime}\right), 118.0\left(\mathrm{C}-2^{\prime}\right), 51.0(\mathrm{OMe}), 39.8\left(\mathrm{C}-4^{\prime}\right), 39.1$ (C-8'), 34.7 (C-12'), $28.0\left(\mathrm{C}-9^{\prime}\right), 27.8$ (C13'), 27.5 (C-1'), $26.4\left(\mathrm{C}-5^{\prime}\right), 25.6$ (C-16'), 17.6 (C-17'), 16.1 (C-7), 15.9 (C-19'); HRESIMS m/z 437.2710 [M-H] (calcd. for $\mathrm{C}_{28} \mathrm{H}_{37} \mathrm{O}_{4}, 437.2692$ ).

\subsection{Diacetyl Sargahydroquinoic Acid (2)}

To sargahydroquinoic acid (1) $(110.0 \mathrm{mg}, 0.26 \mathrm{mmol})$ was added acetic anhydride ( $3 \mathrm{~mL}, 31.8 \mathrm{mmol})$ and pyridine $(2 \mathrm{~mL}, 24.8 \mathrm{mmol})$. The reaction mixture was stirred at room temperature for $30 \mathrm{~h}$. The crude product was acidified with $1 \mathrm{M} \mathrm{HCl}(10 \mathrm{~mL})$ and extracted with EtOAc $(5 \mathrm{~mL} \times 3)$. The organic layer was collected and concentrated under reduced pressure to give a crude product which was further purified by silica gel column chromatography (n-hexane:EtOAc, 7:3) to give compound 2 $(12.8 \mathrm{mg}, 12 \%)$ as a yellow oil. The structure of compound 2 was confirmed by spectroscopic methods, which were in agreement with literature data [6,7]. NMR spectra for compound 2 (Figures S17 and S18) can be found in the Supplementary Materials.

\subsection{Sargaquinol (6) and Sargachromendiol (8)}

To a solution of sargahydroquinoic acid (1) $(140.7 \mathrm{mg}, 0.33 \mathrm{mmol})$ dissolved in anhydrous THF $(5 \mathrm{~mL})$, was added $\mathrm{LiAlH}_{4}(0.104 \mathrm{~g}, 2.74 \mathrm{mmol})$. The reaction mixture was stirred at room temperature, under a nitrogen atmosphere for $1.25 \mathrm{~h}$. The reaction was quenched with a few drops of EtOAc, concentrated and partitioned between EtOAc $\left(10 \mathrm{~mL}^{-2}\right)$ and $\mathrm{H}_{2} \mathrm{O}(5 \mathrm{~mL})$. The organic layer was concentrated under reduced pressure to give a crude product which was purified by silica gel chromatography ( $n$-hexane:EtOAc, $8: 2)$ to give sargaquinol (6) (12.2 $\mathrm{mg}, 30 \%$ ) and the alcohol derivative of sargachromenol (8) (2.8 mg, 3.5\%). The structure of compound 6 was confirmed by spectroscopic methods, which were in agreement with literature data (Table S1) [7]. NMR spectra for compounds 6 (Figures S19 and S20) and 8 (Figures S21 and S22) can be found in the Supplementary Materials.

Sargaquinol (6) yellow oil; ${ }^{1} \mathrm{H}$ NMR $\left(400 \mathrm{MHz}, \mathrm{CDCl}_{3}\right) \delta 6.54(\mathrm{~s}, 1 \mathrm{H})(\mathrm{H}-3), 6.46(\mathrm{~s}, 1 \mathrm{H})(\mathrm{H}-5), 5.15$ $(\mathrm{dd}, J=21.0,13.2 \mathrm{~Hz})\left(\mathrm{H}-2^{\prime}, 6^{\prime}, 14^{\prime}\right), 4.11(\mathrm{~s})\left(\mathrm{H}-18^{\prime}\right), 3.63(\mathrm{t}, J=6.5 \mathrm{~Hz})\left(\mathrm{H}-10^{\prime}\right), 3.12(\mathrm{~d}, J=7.1 \mathrm{~Hz})$

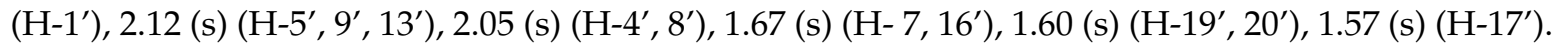
${ }^{13} \mathrm{C}$ NMR $\left(100 \mathrm{MHz}, \mathrm{CDCl}_{3}\right) \delta 188.0$ (C-1), 187.97 (C-4), 148.5 (C-6), 145.9 (C-2), 139.7 (C-3'), 135.0 (C-7'), 133.1 (C-3), 131,2 (C-11'), 132.24 (C-5), 133.7 (C-15'), 124.7 (C-6'), 124.2 (C-14'), 118.1 (C-2'), 71.8 (C-18'), $62.8\left(\mathrm{C}-10^{\prime}\right), 39.8\left(\mathrm{C}-4^{\prime}\right), 39.5\left(\mathrm{C}-8^{\prime}\right), 35.2\left(\mathrm{C}-12^{\prime}\right), 27.1\left(\mathrm{C}-13^{\prime}\right), 27.5\left(\mathrm{C}-1^{\prime}\right), 26.2\left(\mathrm{C}-5^{\prime}\right), 26.3\left(\mathrm{C}-9^{\prime}\right), 25.6$ (C-16'), 17.7 (C-7), 16.11 (C-17'), 16.07 (C-19'), 16.0 (C-20').

Sargachromendiol (8) yellow oil; ${ }^{1} \mathrm{H}$ NMR $\left(400 \mathrm{MHz}, \mathrm{CDCl}_{3}\right) \delta 6.47(\mathrm{~d}, J=2.4 \mathrm{~Hz})(\mathrm{H}-5), 6.32(\mathrm{~d}$, $J=2.5 \mathrm{~Hz})(\mathrm{H}-2), 6.26(\mathrm{~s})\left(\mathrm{H}-2^{\prime}\right), 5.98(\mathrm{t}, J=7.2 \mathrm{~Hz})\left(\mathrm{H}^{\prime} 9^{\prime}\right), 5.57(\mathrm{~d}, J=9.8 \mathrm{~Hz})\left(\mathrm{H}-3^{\prime}\right), 5.12(\mathrm{dt}, J=19.0$, $6.4 \mathrm{~Hz})\left(\mathrm{H}-5^{\prime}, 14^{\prime}\right), 2.59\left(\mathrm{q}, J=7.3 \mathrm{~Hz}\left(\mathrm{H}-8^{\prime}\right), 2.27(\mathrm{t}, J=7.4 \mathrm{~Hz}), 2.13(\mathrm{~s})\left(\mathrm{H}-12^{\prime}\right), 2.09-2.04(\mathrm{~m})\left(\mathrm{H}-4^{\prime}, 7^{\prime}\right)\right.$, $1.68(\mathrm{~s})(\mathrm{H}-8), 1.58(\mathrm{~d}, J=3.5 \mathrm{~Hz})\left(\mathrm{H}-17^{\prime}, 19^{\prime}\right), 1.36(\mathrm{~s})\left(20^{\prime}\right) ;{ }^{13} \mathrm{C} \mathrm{NMR}\left(100 \mathrm{MHz}, \mathrm{CDCl}_{3}\right) \delta 148.6(\mathrm{C}-5)$, 145.0 (C-10'), 144.8 (C-8), 134.7 (C-7'), 131.8 (C-15'), 130.6 (C-11'), 126.3 (C-3), 124.7 (C-6'), 124.1 (C-1'), 122.9 (C-14'), 121.3 (C-2), 117.0 (C-4), 110.3 (C-6), 77.8 (C-3'), 60.3 (C-18'), 40.7 (C-4'), 39.8 (C-8'), 35.1 
(C-12'), $35.3\left(\mathrm{C}-12^{\prime}\right), 27.0\left(\mathrm{C}-9^{\prime}\right), 26.1\left(\mathrm{C}-13^{\prime}\right), 25.9\left(\mathrm{C}-20^{\prime}\right), 25.7\left(\mathrm{C}-16^{\prime}\right), 22.6\left(\mathrm{C}-5^{\prime}\right), 17.7\left(17^{\prime}\right), 15.9$ (C-7), $15.5\left(\mathrm{C}-19^{\prime}\right)$.

\subsection{Z-sargaquinal (4)}

To a solution of sargaquinol (6) $(37.2 \mathrm{mg}, 0.09 \mathrm{mmol})$ dissolved in anhydrous $\mathrm{CH}_{2} \mathrm{Cl}_{2}(8 \mathrm{~mL})$, Dess-Martin Periodinane $(107 \mathrm{mg}, 0.26 \mathrm{mmol}$ ) was added. The reaction mixture was stirred at room temperature for $2 \mathrm{~h}$ after which it was quenched with $\mathrm{CH}_{2} \mathrm{Cl}_{2}(10 \mathrm{~mL})$ and de-ionized water $(10 \mathrm{~mL})$. The organic phase was separated and washed with saturated solutions of $\mathrm{NaHCO}_{3}(10 \mathrm{~mL} \times 3)$ and $\mathrm{Na}_{2} \mathrm{~S}_{2} \mathrm{O}_{3}$ $(10 \mathrm{~mL} \times 3)$, dried over anhydrous $\mathrm{Na}_{2} \mathrm{SO}_{4}$ and concentrated under reduced pressure. The crude product was purified by silica gel column chromatography ( $n$-hexane:EtOAc, 8:2) to give compound 4 $(42 \%, 14.9 \mathrm{mg})$, as a yellow oil. The structure of compound 4 was confirmed by spectroscopic methods, which were in agreement with literature data (Table S1) [7]. NMR spectra for compound 4 (Figures S23 and S24) can be found in the Supplementary Materials.

\subsection{Antiplasmodial Assays}

All compounds were tested in triplicate against the chloroquine-resistant Gambian FCR-3 strain of P. falciparum. The in vitro erythrocytic stage of the parasite was maintained using the method outlined by Trager and Jensen [8]. The antimalarial activity of the compounds was determined using the tritiated hypoxanthine incorporation assay using a $0.5 \%$ parasitaemia and $1 \%$ haematocrit [9]. All assays were carried out using untreated parasites and uninfected red blood cells as controls. The concentration that inhibited $50 \%$ parasite growth ( $\mathrm{IC}_{50}$ value) was determined from the log sigmoid dose response curve using GraphPad Prism. Quinine was used as the reference antiplasmodial agent. The selectivity index for the compounds was determined from the ratio of cytotoxicity $\mathrm{IC}_{50}$ to antimalarial $\mathrm{IC}_{50}$.

\subsection{Cytotoxicity Assay}

All compounds were tested in triplicate against MDA-MB-231 breast carcinoma cells, which were purchased from the ATCC (Catalogue number HTB-26, Manassas, VA, USA). The cytotoxicity of the compounds was determined using the WST-1 assay method (Roche). The cells were treated with a range of concentrations of the test compounds or vehicle control (DMSO). Cells treated with DMSO were considered to represent $100 \%$ viability and the viability of cells at each dose was represented relative to this value. The concentration resulting in a decrease of cell viability to $50 \%$ was calculated from the linear portion of the dose response curve.

\section{Results and Discussion}

\subsection{Isolation and Synthetic Modification of Sargahydroquinoic Acid Derivatives}

Sargahydroquinoic acid (1) is the major component of the $\mathrm{CH}_{2} \mathrm{Cl}_{2}-\mathrm{MeOH}$ extract of Sargassum incisifolium and has also been reported from several other Sargassum spp. [5-7]. This compound slowly converts to sargaquinoic acid (3) and sargachromenol (7) on storage of the seaweed, the extract and during purification. Specimens of S. incisifolium (PA071b) were collected from Port Alfred on the south eastern coast of South Africa and extracted with $\mathrm{CH}_{2} \mathrm{Cl}_{2}-\mathrm{MeOH}$. The crude extract was first fractionated by silica gel column chromatography, followed by normal or reversed phase HPLC to give compounds 1, 3, 7 and 9 . The identities of all isolated compounds were confirmed by comparison of their NMR spectroscopic data (Table S1) to literature values [5]. The above protocol yielded sufficient quantities of $\mathbf{1}$ to perform structural modifications and biological assays.

Sargaquinoic acid (3) is normally isolated from fresh seaweed in relatively small quantities; however, it can be produced more efficiently by the oxidation of $\mathbf{1}[7,10]$. Thus, treatment of 1 with $\mathrm{Ag}_{2} \mathrm{O}$ gave 3 in moderate to good yields. Interestingly, although this conversion is facile, we consistently observed a series of unusual peaks between $\delta_{\mathrm{H}} 7$ and 8 in the ${ }^{1} \mathrm{H}$ NMR spectrum of the crude reaction 
product. The compound (10) responsible for these peaks was isolated and its structure was elucidated by NMR spectroscopy and mass spectrometry.

The HRESIMS spectrum of compound 10 showed a molecular ion peak at $m / z 419.2222$ [M-H] which corresponds to a molecular formula of $\mathrm{C}_{27} \mathrm{H}_{31} \mathrm{O}_{4}$. Characteristic deshielded methine resonances at $\delta_{\mathrm{H}} 8.00(\mathrm{~d}, J=7.9), \delta 7.98(\mathrm{~s})$ and $\delta 7.51(\mathrm{~d}, J=7.9)$ were evident in its ${ }^{1} \mathrm{H}$ NMR spectrum. In addition, one of the aromatic singlets had shifted downfield from $\delta_{\mathrm{H}} 6.46$ in 3 to $\delta_{\mathrm{H}} 6.81$ in 10. Data from the ${ }^{13} \mathrm{C}$ NMR spectrum of compound 10 revealed no change in the number of carbon atoms when compared to the starting material (1). It revealed the presence of two quinone carbonyls signals at $\left(\delta_{C} 185.4\right.$ and $\left.\delta 185.4\right)$ and a carboxylic acid moiety $\left(\delta_{C} 171.9\right)$. In addition, the DEPT-135 NMR spectrum indicated the loss of one methyl signal $\left(\delta_{C} 16.1, C-20^{\prime}\right)$ and a methylene signal $\left(\delta_{C} 27.5, C-1^{\prime}\right)$ when compared to 3 , together with the appearance of two additional olefinic methine signals at $\delta_{\mathrm{C}}$ $126.7\left(\mathrm{C}-1^{\prime}\right)$ and $125.9\left(\mathrm{C}-20^{\prime}\right)$. HMBC correlations (Figure 2) from the doublet at $\delta_{\mathrm{H}} 8.00\left(\mathrm{H}-1^{\prime}\right)$ to carbon signals at $\delta_{\mathrm{C}} 126.7\left(\mathrm{C}-1^{\prime}\right)$ and $\delta_{\mathrm{C}} 133.8\left(\mathrm{C}-2^{\prime}\right)$; the methine signal at $\delta_{\mathrm{H}} 7.51\left(\mathrm{H}-2^{\prime}\right)$ to the carbon signal at $\delta_{\mathrm{C}} 125.9\left(\mathrm{C}-20^{\prime}\right)$ and from $\delta_{\mathrm{H}} 7.86\left(\mathrm{H}-20^{\prime}\right)$ to carbon signals at $\delta_{\mathrm{C}} 36.2\left(\mathrm{C}-4^{\prime}\right)$ and $\delta_{\mathrm{C}} 185.4(\mathrm{C}-4)$, allowed for the assignment of the naphthoquinone moiety. All other spectroscopic data are consistent with a polyprenyl side chain with a $6^{\prime} E, 10^{\prime} Z$-double bond geometry (as in 3). We assigned the name sarganaphthoquinoic acid to this new compound. A related compound, chabrolonaphthoquinone, had previously been reported from the Taiwanese soft coral, Nephthea chabrolii [11]. The main differences between the two compounds are the methyl substituent at C-6 and the 10-double bond geometry in compound 10.

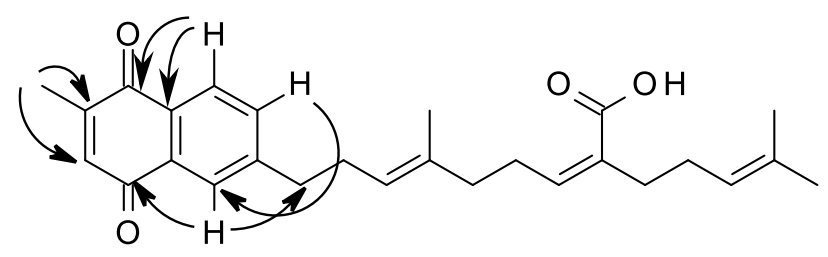

Figure 2. Key HMBC correlations for $\mathbf{1 0 .}$

The direct conversion of prenylated hydroquinones to naphthoquinones is uncommon and presents a novel approach to the synthesis of this important group of compounds. To the best of our knowledge there is only a single report describing the formation of a naphthoquinone as a side-product in the synthesis of chromenes from prenylated quinones [12]. Naphthoquinones are typically synthesized by Diels-Alder reactions between $p$-benzoquinones and dienes or by the prenylation of halogenated naphthoquinone moieties [13-15]. Compound $\mathbf{1 0}$ is proposed to form via tautomerism and oxidation of the intermediate quinone (3) followed by $6 \pi$ electrocyclization and further oxidation (Scheme 1).<smiles>[R]C(C)=CCc1cc(O)cc(C)c1O</smiles><smiles>[R]C(=C)/C=C\c1cc(O)cc(C)c1O</smiles>

Scheme 1. Proposed mechanism for the synthesis of sarganaphthoquinoic acid (10). 
In order to establish preliminary structure-antiplasmodial activity relationships for this series of sargahydroquinoic acid derivatives, we focused our attention on modification of the carboxylic acid and quinone moieties. Acetylation of $\mathbf{1}$ with acetic anhydride/pyridine gave the diacetate (2), while its reduction with lithium aluminium hydride gave a mixture of sargaquinol (6) and sargachromendiol (8). The facile conversion of the hydroquinone to a mixture of the quinone and chromene on exposure to air is often seen in this series of compounds [6,7]. Spectroscopic evidence for the identity of alcohols 6 and 8 were provided by the disappearance of the ${ }^{13} \mathrm{C}$ NMR signal due to the carboxylic acid group at $\delta_{C} 172 \mathrm{ppm}$ and the appearance of an oxymethylene carbon signal at $\delta_{C} 60.3 \mathrm{ppm}$ in both compounds.

Mild oxidation of 6 with Dess-Martin periodinane, gave 10Z-sargaquinal (4). The structures of aldehydes 4 and 9 were confirmed by comparison of their spectroscopic data with literature values [5,7]. A comparison of the ${ }^{1} \mathrm{H}$ NMR spectra of the natural and semi-synthetic aldehydes revealed differences in chemical shifts of both proton and carbon atoms associated with the aldehyde group. The ${ }^{1} \mathrm{H}$ and ${ }^{13} \mathrm{C}$ NMR spectra of the semi-synthetic aldehyde (4) showed signals at $\delta_{\mathrm{H}} 10.1$ and $\delta_{\mathrm{C}} 190.9 \mathrm{ppm}$ compared to $\delta_{\mathrm{H}} 9.55$ and $\delta_{\mathrm{C}} 205.4 \mathrm{ppm}$ in the natural aldehyde (9). ${ }^{1} \mathrm{H}-{ }^{1} \mathrm{H}$ NOESY correlations in both compounds confirmed the difference in the geometry of the $\Delta^{10}$ double bond with the semi-synthetic aldehyde (4) bearing a 10Z-geometry and the natural aldehyde (9) a 10E-geometry. The formation of $2^{\prime} E, 6^{\prime} E, 10^{\prime} Z$-sargaquinal (4) from $2^{\prime} E, 6^{\prime} E, 10^{\prime} Z$-sargahydroquinoic acid (1) has been reported in the literature [7]. However, this is the first report of its ${ }^{13} \mathrm{C}$ and $2 \mathrm{D}$ NMR data.

Interestingly, methylation of $\mathbf{1}$ with dimethylsulphate/potassium carbonate did not produce the dimethyl ether, but instead produced sargaquinoic acid methyl ester (5). This was confirmed by the appearance of an additional methyl signal at $\delta_{C} 51.0$ and an upfield shift of the C-18' carbonyl signal from $\delta_{\mathrm{C}} 172$ to $\delta 168.4 \mathrm{ppm}$ in the ${ }^{13} \mathrm{C}$ NMR spectrum of 5 (Table S1).

\subsection{Biological Assays}

The ten sargahydroquinoic acid derivatives were assessed for both antiplasmodial and cytotoxic activity against the chloroquine-resistant Gambian FCR-3 strain of P. falciparum and MDA-MB-231 breast cells, respectively (Table 2). All compounds showed moderate to good antiplasmodial activity. However, the most promising compound in this series is the naphthoquinone $\mathbf{1 0}$ which not only revealed good antiplasmodial activity $\left(\mathrm{IC}_{50} 5.4 \mu \mathrm{M}\right)$, but also very low cytotoxicity $\left(\mathrm{IC}_{50} 2410 \mu \mathrm{M}\right)$, resulting in a high selectivity index of 443. Sargaquinoic acid (3) also shows promising antiplasmodial activity $\left(\mathrm{IC}_{50} 10.8 \mu \mathrm{M}\right)$, but is slightly more toxic $\left(\mathrm{IC}_{50} 658 \mu \mathrm{M}\right)$ than 10 . It appears that the carboxylic acid in the prenyl side chain is important for activity since both aldehydes (4) and (9) and the alcohol (6) showed decreased antiplasmodial activity. The quinone/naphthoquinone scaffold is present in several antimalarial natural products and drugs [16]. It is therefore likely that the mode of action of the compounds reported here is related to this important pharmacophore [16-20].

Table 2. Bioassay results for compounds 1-10.

\begin{tabular}{ccccc}
\hline \multirow{2}{*}{ Compound } & \multicolumn{3}{c}{ IC $_{\mathbf{5 0}}(\boldsymbol{\mu M})$} & \multirow{2}{*}{ Selectivity Index } \\
\cline { 2 - 4 } & $\mathbf{D 1 0}^{\mathbf{1}}$ & FCR-3 & MDA-MB-231 & \\
\hline Sargahydroquinoic acid (1) & 15.2 & 38.6 & 70 & 1.8 \\
Sargahydroquinoic acid di-acetate (2) & - & 84.3 & 286 & 3.4 \\
Sargaquinoic acid (3) & 12.0 & 10.8 & 658 & 60.9 \\
10Z-sargaquinal (4) & - & 72.6 & 211 & 2.9 \\
Sargaquinoic acid methyl ester (5) & - & 8.2 & 70 & 8.6 \\
Sargaquinol (6) & - & 93.1 & 99 & 0.1 \\
Sargachromenol (7) & - & 114.8 & 56 & 5.5 \\
Sargachromendiol (8) & - & 34.2 & 187 & 0.7 \\
10E-sargaquinal (9) & 2.0 & 104.4 & 69 & 443 \\
Sarganaphthoquinone (10) & - & 5.4 & 2410 & - \\
Quinine & & 0.17 & - & \\
\hline
\end{tabular}

${ }^{1}$ From reference [5]. 


\section{Conclusions}

In this study we isolated the relatively abundant antiplasmodial natural product, sargahydroquinoic acid (1) and converted it to several analogs which were evaluated for antiplasmodial and cytotoxic activity. The serendipitous formation of sarganaphthoquinoic acid (10) gave a compound with good antiplasmodial activity while being almost non-toxic. Due to the small number of compounds no clear structure activity relationships can be established, however it appears that the presence of a quinone and carboxylic acid are important for selective activity against $P$. falciparum. Further studies are warranted to explore the mode of action of these compounds and to further improve on its antiplasmodial activity.

Supplementary Materials: The following are available online at http://www.mdpi.com/2305-6320/6/2/47/s1, Scheme S1: Isolation of compounds 1, 3, 7 and 9, Table S1: Comparison of ${ }^{13} \mathrm{C}$ NMR data for compounds 1, 3-9, Figure S1: ${ }^{1} \mathrm{H}$ NMR spectrum of sargahydroquinoic acid (1) $\left(400 \mathrm{MHz}, \mathrm{CDCl}_{3}\right)$, Figure $\mathrm{S}^{2}:{ }^{13} \mathrm{C}$ NMR spectrum of sargahydroquinoic acid (1) $\left(100 \mathrm{MHz}, \mathrm{CDCl}_{3}\right)$, Figure S3: ${ }^{1} \mathrm{H} \mathrm{NMR}$ spectrum of sargaquinoic acid (3) (400 MHz, CDCl $)$, Figure S4: ${ }^{13} \mathrm{C}$ NMR spectrum of compound $3\left(400 \mathrm{MHz}, \mathrm{CDCl}_{3}\right)$, Figure S5: ${ }^{1} \mathrm{H}$ NMR spectrum of sargachromenol (7) $\left(400 \mathrm{MHz}, \mathrm{CDCl}_{3}\right)$, Figure $\mathrm{S6}:{ }^{13} \mathrm{C}$ NMR spectrum of sargachromenol (7) $(100 \mathrm{MHz}$, $\left.\mathrm{CDCl}_{3}\right)$, Figure S7: ${ }^{1} \mathrm{H}$ NMR spectrum of $10^{\prime} \mathrm{E}$-sargaquinal (9) $\left(400 \mathrm{MHz}, \mathrm{CDCl}_{3}\right)$, Figure $88:{ }^{13} \mathrm{C}$ NMR spectrum of 10'E-sargaquinal (9) (100 MHz, $\left.\mathrm{CDCl}_{3}\right)$, Figure S9: ${ }^{1} \mathrm{H}$ NMR spectrum of sarganaphthoquinoic acid (10) $\left(400 \mathrm{MHz}, \mathrm{CDCl}_{3}\right)$, Figure S10: ${ }^{13} \mathrm{C}$ NMR spectrum of sarganaphthoquinoic acid $(\mathbf{1 0})\left(100 \mathrm{MHz}, \mathrm{CDCl}_{3}\right)$, Figure S11: DEPT-135 NMR spectrum of sarganaphthoquinoic acid (10) $\left(100 \mathrm{MHz}, \mathrm{CDCl}_{3}\right)$, Figure S12: HSQC NMR spectrum of sarganaphthoquinoic acid (10) $\left(\mathrm{CDCl}_{3}\right)$, Figure S13: COSY NMR spectrum of sarganaphthoquinoic acid (10) $\left(\mathrm{CDCl}_{3}\right)$, Figure S14: HMBC NMR spectrum of sarganaphthoquinoic acid (10) $\left(\mathrm{CDCl}_{3}\right)$. Figure S15: ${ }^{1} \mathrm{H} \mathrm{NMR}$ spectrum of sargaquinoic acid methyl ester (5) $\left(400 \mathrm{MHz}, \mathrm{CDCl}_{3}\right)$, Figure $\mathrm{S} 16:{ }^{13} \mathrm{C} \mathrm{NMR}$ spectrum of sargaquinoic acid methyl ester (5) (100 MHz), Figure S17: ${ }^{1} \mathrm{H}$ NMR spectrum of sargahydroquinoic acid diacetate (2) $(400 \mathrm{MHz}$, $\left.\mathrm{CDCl}_{3}\right)$, Figure S18: ${ }^{13} \mathrm{C}$ NMR spectrum of sargahydroquinoic acid diacetate (2) $\left(100 \mathrm{MHz}, \mathrm{CDCl}_{3}\right)$, Figure S19: ${ }^{1} \mathrm{H}$ NMR spectrum of sargaquinol (6) (400 $\left.\mathrm{MHz}, \mathrm{CDCl}_{3}\right)$, Figure S20: ${ }^{13} \mathrm{C}$ NMR spectrum of sargaquinol (6) $\left(100 \mathrm{MHz}, \mathrm{CDCl}_{3}\right)$, Figure S21: ${ }^{1} \mathrm{H}$ NMR spectrum of sargachromendiol $(8)\left(400 \mathrm{MHz}, \mathrm{CDCl}_{3}\right)$, Figure S22: ${ }^{13} \mathrm{C}$ NMR spectrum of sargachromendiol (8) (100 MHz, $\left.\mathrm{CDCl}_{3}\right)$, Figure S23: ${ }^{1} \mathrm{H}$ NMR spectrum of $10^{\prime} \mathrm{Z}$-sargaquinal (4) $\left(600 \mathrm{MHz}, \mathrm{CDCl}_{3}\right)$, Figure S24: ${ }^{13} \mathrm{C}$ NMR spectrum of 10 'Z-sargaquinal (4) $\left(100 \mathrm{MHz}, \mathrm{CDCl}_{3}\right)$.

Author Contributions: D.R.B. conceived and designed the work. T.C.M. isolated the natural products and synthesized the analogs, R.L.v.Z. and D.C.H conducted the antiplasmodial assays. Cytotoxicity studies were done by A.L.E. D.R.B. and T.C.M. drafted the manuscript. All authors read and approved the final version of manuscript.

Funding: This research was funded by Rhodes University, University of the Witwatersrand and the University of the Western Cape. A.L.E is funded by the South African Research Chairs Initiative of the Department of Science and Technology (DST) and National Research Foundation of South Africa (NRF) (Grant No 98566), and National Research Foundation CPRR (Grant No 105829).

Acknowledgments: T.C.M. acknowledges Rhodes University and the Andrew W. Mellon Foundation for a Masters scholarship.

Conflicts of Interest: The authors declare no conflict of interest.

\section{References}

1. Okombo, J.; Chibale, K. Recent updates in the discovery and development of novel antimalarial drug candidates. Med. Chem. Commun. 2018, 9, 437-453. [CrossRef] [PubMed]

2. World Health Organization. World Malaria Report; World Health Organization: Geneva, Switzerland, 2018.

3. Amato, R.; Pearson, R.D.; Almagro-Garcia, J.; Amaratunga, C.; Lim, P.; Suon, S.; Sreng, S.; Drury, E.; Stalker, J.; Miotto, O.; et al. Origins of the current outbreak of multidrug-resistant malaria in southeast Asia: A retrospective genetic study. Lancet Infect. Dis. 2018, 18, 337-345. [CrossRef]

4. Fernández-Álvaro, E.; Hong, W.D.; Nixon, G.L.; O’Neill, P.M.; Calderón, F. Antimalarial chemotherapy: Natural product inspired development of preclinical and clinical candidates with diverse mechanisms of action. J. Med. Chem. 2016, 59, 5587-5603. [CrossRef] [PubMed]

5. Afolayan, A.F.; Bolton, J.J.; Lategan, C.A.; Smith, P.J.; Beukes, D.R. Fucoxanthin, tetraprenylated toluquinone and toluhydroquinone metabolites from Sargassum heterophyllum inhibit the in vitro growth of the malaria parasite Plasmodium falciparum. Z. Naturforsch. 2008, 63c, 848-852. [CrossRef] 
6. Segawa, M.; Shirahama, H. New plastoquinones from the brown alga Sargassum sagamianum var. yezoense. Chem. Lett. 1987, 1365-1366. [CrossRef]

7. Kusumi, T.; Ishitsuka, M.; Kinoshita, T.; Kakisawa, H.; Shibata, Y. Structures of new plastoquinones from the brown alga Sargassum serratifolium. Chem. Lett. 1979, 8, 277-278. [CrossRef]

8. Trager, W.; Jensen, J.B. Human malaria parasites in continuous culture. Science 1976, 193, 673-675. [CrossRef] [PubMed]

9. Desjardins, R.E.; Canfield, C.J.; Haynes, J.D.; Chulay, J.D. Quantitative assessment of antimalarial activity in vitro by a semiautomated microdilution technique. Antimicrob. Agents Chemother. 1979, 16, 710-718. [CrossRef] [PubMed]

10. Perez-Castorena, A.; Arciniegas, A.; Apan, M.T.R.; Villasenor, J.L.; de Vivar, A. Evaluation of the anti-inflammatory and antioxidant activities of the plastoquinones derivatives isolated from Roldana barba-johanis. Planta Med. 2002, 68, 645-647. [CrossRef] [PubMed]

11. Sheu, J.-H.; Su, J.-H.; Sung, P.-J.; Wang, G.-H.; Dai, H. Novel meroditerpenoid-related metabolites from the formosan soft coral Nephthea chabrolii. J. Nat. Prod. 2004, 67, 2048-2052. [CrossRef] [PubMed]

12. Chan, S.T.S.; Pullar, M.A.; Khalil, I.M.; Allouche, E.; Barker, D.; Copp, B.R. Bio-inspired dimerisation of prenylated quinones directed towards the synthesis of the meroterpenoid natural products, the scabellones. Tetrahedron Lett. 2015, 56, 1486-1488. [CrossRef]

13. Alonso, M.A.; Lopez-Alvarado, P.; Avendano, C.; Menendez, J.C. Regioselective Diels-Alder reactions of 3-vinylindoles with quinones. Lett. Org. Chem. 2004, 1, 20-22. [CrossRef]

14. de Koning, C.B.; Rousseau, A.L.; van Otterlo, W.A.L. Modern methods for the synthesis of substituted naphthalenes. Tetrahedron 2003, 59, 7-36. [CrossRef]

15. Couladouros, E.A.; Plyta, Z.F.; Papageorgiou, V.P. A general procedure for the efficient synthesis of (alkylamino)naphthoquinones. J. Org. Chem. 1996, 61, 3031-3033. [CrossRef] [PubMed]

16. Nixon, G.L.; Moss, D.M.; Shone, A.E.; Lalloo, D.G.; Fisher, N.; O’Neill, P.M.; Ward, S.A.; Biagini, G.A. Antimalarial pharmacology and therapeutics of atovaquone. J. Antimicrob. Chemother. 2013, 68, 977-985. [CrossRef] [PubMed]

17. Olliaro, P. Mode of action and mechanisms of resistance for antimalarial drugs. Pharmacol. Ther. 2001, 89, 207-219. [CrossRef]

18. Vennerstrom, J.L.; Eaton, J.W. Oxidants, oxidant drugs, and malaria. J. Med. Chem. 1988, 31, $1269-1277$. [CrossRef] [PubMed]

19. Brandão, G.C.; Rocha Missias, F.C.; Arantes, L.M.; Soares, L.F.; Roy, K.K.; Doerksen, R.J.; Braga de Oliveira, A.; Pereira, G.R. Antimalarial naphthoquinones. Synthesis via click chemistry, in vitro activity, docking to PfDHOD and SAR of lapachol-based compounds. Eur. J. Med. Chem. 2018, 145, 191-205. [CrossRef] [PubMed]

20. Imperatore, C.; Persico, M.; Senese, M.; Aiello, A.; Casertano, M.; Luciano, P.; Basilico, N.; Parapini, S.; Paladino, A.; Fattorusso, C.; et al. Exploring the antimalarial potential of the methoxy-thiazinoquinone scaffold: Identification of a new lead candidate. Bioorg. Chem. 2019, 85, 240-252. [CrossRef] [PubMed]

(C) 2019 by the authors. Licensee MDPI, Basel, Switzerland. This article is an open access article distributed under the terms and conditions of the Creative Commons Attribution (CC BY) license (http://creativecommons.org/licenses/by/4.0/). 